\title{
Níveis de tiroglobulina prévia à ablação e persistência / recorrência precoce do câncer diferenciado da tireoide
}

\author{
Niveles de tiroglobulina previo a la ablación y persistencia / \\ recurrencia precoz del cáncer diferenciado de tiroides \\ Pre-Ablation Thyroglobulin Levels and Persistence / \\ Recurrence Associated to Early Differentiated Thyroid Cancer \\ Arturo Mejía López MD, Esp.', José Rafael Tovar Cuevas MSc, PhD. ${ }^{2}$, \\ Claudia Teresa Gutiérrez Villamil MD, Esp. ${ }^{3}$
}

Recibido 17 de septiembre de 2012 • Aceptado: 13 de noviembre de 2013

Doi: dx.doi.org/10.12804/revsalud12.1.2014.01

Para citar este artículo: Mejía-López A, Tovar JR, Gutiérrez-Villamil CT. Níveis de tiroglobulina prévia à ablação e persistência / recorrência precoce do câncer diferenciado da tireoide. Rev Cienc Salud 2014; 12 (1): 9-21. doi: dx.doi.org/10.12804/revsalud12.1.2014.01

\section{Resumo}

Introdução: $\mathrm{O}$ câncer diferenciado de tireoide é a neoplasia endócrina mais frequente no mundo e a sua incidência cresce de forma acelerada. Pesquisaram-se a relação entre os níveis de tiroglobulina (Tg) prévia à ablação e a persistência/recorrência precoce do câncer diferenciado da tireoide. Materiais e métodos: Avaliaram-se 91 pacientes com câncer papilar de tireoide que foram submetidos à ablação pós-cirúrgica com iodo radiativo, numa clínica especializada, no período entre janeiro de 2006 e janeiro de 2010. A análise dos dados foi realizada utilizando-se SPSS 20 para Windows e a hipótese de pesquisa foi avaliada por meio de métodos próprios da estatística não paramétrica. Resultados: A doença progrediu em 20 pacientes durante o primeiro ano pós-ablação e se encontrou relação significativa entre a Tg pré-ablação e o estado da doença ao final desse período $(p=0,000)$. No grupo de indivíduos que apresentaram progressão da doença, não foram observadas mudanças significativas entre os níveis da Tg avaliados seis e doze meses depois da ablação $(p=0,554)$. É importante ressaltar que os indivíduos com níveis de Tg prévia à ablação menores ou iguais a $2,7 \mathrm{ng} / \mathrm{mL}$ não apresentaram recorrência/persistência e que $80 \%$ dos casos corresponderam a indivíduos com níveis iniciais maiores a $24 \mathrm{ng} / \mathrm{mL}$. Conclusão: Nos pacientes

\footnotetext{
Departamento de Medicina Nuclear, Fundación Cardioinfantil, Instituto de Cardiología, Bogotá, Colombia.

2 Escuela de Medicina y Ciencias de la Salud, Universidad del Rosario, Bogotá, Colombia.

3 Departamento de Medicina Nuclear, Fundación Cardioinfantil, Instituto de Cardiología, Bogotá, Colombia. Autor para correspondencia:Arturo Mejía López, amejial@cardioinfantil.org
} 
com câncer papilar de tireoide o nível sérico da Tg pré-ablação está relacionado com o estado da doença ao final do primeiro ano pós-ablação. A persistência/recorrência é menos frequente com níveis baixos e mais frequente com níveis altos.

Palavras-chave: tiroglobulina, neoplasias, glândula tireoide, prognóstico.

\section{Resumen}

Introducción: El cáncer diferenciado de tiroides es la neoplasia endocrina más frecuente en el mundo y su incidencia crece de manera acelerada. Se investigó la relación entre los niveles de tiroglobulina ( $\mathrm{Tg}$ ) previo a la ablación y la persistencia/recurrencia precoz del cáncer diferenciado de tiroides. Materiales y métodos: Se evaluaron 91 pacientes con cáncer papilar de tiroides que fueron sometidos a la ablación posquirúrgica con yodo radioactivo, en una clínica especializada, en el periodo de enero de 2006 a enero de 2010. El análisis de los datos fue realizado utilizando SPSS 20 para Windows y la hipótesis de investigación fue evaluada a través de métodos propios de la estadística no paramétrica. Resultados: La enfermedad avanzó en 20 pacientes durante el primer año posablación y se encontró relación significativa entre la Tg pre-ablación y el estado de la enfermedad al final de eses periodo $(p=0,000)$. En el grupo de individuos que presentaron avance de la enfermedad, no fueron observados cambios significativos entre los niveles de la $\mathrm{Tg}$, evaluados seis y doce meses después de la ablación $(\mathrm{p}=0,554)$. Es importante resaltar que los individuos con niveles de Tg previo a la ablación menores o iguales a $2,7 \mathrm{ng} / \mathrm{mL}$ no presentaron recurrencia/persistencia y que el $80 \%$ de los casos correspondieron a individuos con niveles iniciales mayores a $24 \mathrm{ng} / \mathrm{mL}$. Conclusiones: En los pacientes con cáncer papilar de tiroides el nivel sérico de la Tg preablación, está relacionado con el estado de la enfermedad al final del primer año posablación. La persistencia/recurrencia es menos frecuente con niveles bajos, y más frecuente con niveles altos.

Palabras clave: tiroglobulina, neoplasias, glándula tiroides, pronóstico.

\section{Abstract}

Introduction: Differentiated thyroid cancer is the most frequent endocrine neoplasm in the world and its incidence is growing rapidly. The relationship between levels of pre-ablation thyroglobulin (Tg) and early persistence/recurrence of differentiated thyroid cancer was studied. Materials and Methods: 91 patients with papillary thyroid cancer who underwent post-surgical ablation with radioactive iodine registered in the Fundación Cardioinfantil between January 2006 and January 2010 were evaluated. The analysis of the results was performed using the SPSS statistical package and the research hypothesis was evaluated using nonparametric methods. Results: The disease progressed in 20 patients during the first year post-ablation, at the end of this period $(p=0.000)$ a significant relationship between pre-ablation $\mathrm{Tg}$ and disease status was found. In the group of individuals by whom the disease progressed there was no significant change in Tg between the first and the second semester post-ablation $(\mathrm{p}=0.554)$; there were no cases of recurrence/persistence in those with levels less than or equal to $2.7 \mathrm{ng} / \mathrm{mL} ; 80 \%$ of these cases involved individuals with initial levels higher than $24 \mathrm{ng} / \mathrm{mL}$. Conclusion: In patients with papillary thyroid cancer, 
the serum pre-ablation Tg is related to the disease status at the end of the first year post-ablation. The persistence/recurrence is less frequent in low levels and more frequent in higher levels.

Key words: Thyroglobulin, neoplasms, thyroid gland, prognosis.

\section{Introdução}

O câncer diferenciado de tireoide (CDT) é a neoplasia endócrina mais frequente no mundo, afeta mais comumente as mulheres e a maior incidência se apresenta entre a $5^{\mathrm{a}}$ e a $8^{\mathrm{a}}$ década da vida (1).

Os carcinomas diferenciados de tireoide são tratados com tireodiectomia e posterior ablação e supressão do hormônio TSH, combinação que permite reduzir a persistência ou recorrência do câncer. Nos últimos anos, a Tiroglobulina (Tg) tem se constituído em um marcador tumoral de grande importância no tratamento e seguimento aos pacientes com CDT, já que é um paraclínico disponível e altamente sensível para detectar persistência ou recorrência de tumores $(2,5)$; embora a utilidade clínica da Tg medida depois da tireodiectomia, e imediatamente antes da ablação com I-131, não seja clara (6). Resultados de algumas pesquisas sugerem que níveis altos de $\mathrm{Tg}$ podem indicar aparição precoce de persistência, recorrência, metástase ou resposta terapêutica, estabelecendo-se diversos limiares $(1-67,9 \mathrm{ng} / \mathrm{DL})$ arbitrários que têm gerado resultados diversos, o que não tem permitido chegar a um consenso sobre qual é o valor mais apropriado para estabelecer o limite da proteína (7-14). É assim como se apresenta a necessidade de aprofundar a pesquisa do limiar e do valor preditivo da Tg pré-ablação para se ter maior clareza sobre a utilidade clínica da mesma em situações onde seja necessário realizar ablação, ajustar a dose de radioiodo ou fazer seguimento no primeiro ano depois da ablação.
A medição da Tg prévia à ablação pós-cirúrgica é uma prática generalizada e rotineira, entretanto, os clínicos nem sempre têm clareza sobre a utilidade da Tg como marcador tumoral, sendo a medição considerada mais como parâmetro basal, sem se considerar seu valor prognóstico e determinante no seguimento apropriado aos pacientes.

No momento prévio à ablação, a Tg encontrase liberada ou estimulada, constituindo-se numa expressão da persistência de células tireóideas normais ou malignas e seu nível é um indicador da quantidade dessas células. Baseado nisso, surge o interesse de conhecer como a quantidade da Tg pré-ablação pode ser um marcador que permite prognosticar a presença de recorrência/ persistência tumoral um ano depois da terapia com ablação, já que, durante esse período, apresenta-se a maior frequência de recaídas (mais da terceira parte do total de recaídas em 10 anos) (15). Portanto, tem que ser o período de maior seguimento.

Existem, até o momento, somente dois estudos que têm avaliado o desempenho da $\mathrm{Tg}$ como marcador de sucesso do tratamento com ablação, os quais utilizaram curvas características de operação. No primeiro estudo, o sucesso foi definido como $\mathrm{Tg}$ suprimida não detectável no período compreendido entre 6 e 12 meses de seguimento, verificando-se que o melhor desempenho do teste (Tg) para predizer ablação bem-sucedida foi o valor de $10 \mathrm{ng} / \mathrm{mL}$, para o qual os níveis de sensibilidade e especificidade foram $85,7 \%$ e $83,6 \%$, respectivamente, indicando uma alta capacidade discriminatória (8). Porém, 
nesse estudo não se considerou a avaliação dos níveis da Tg liberada nem outros testes imagenológicos ou histopatológicos para determinar o sucesso da ablação (5).

A segunda pesquisa encontrada é um estudo correlacional entre os níveis da Tg pós-cirúrgica e o seguimento realizado depois da terapia que inclui a definição do estágio 12 meses depois. Neste estudo, verificou-se que, quatro semanas depois da cirurgia, $94 \%$ dos pacientes com uma $\mathrm{Tg}$ maior de 4,5 $\mu \mathrm{g} / \mathrm{L}$ apresenta metástase na avaliação pós-cirurgia e que $93 \%$ dos pacientes livres de doença 12 meses depois da cirurgia tem uma Tg menor de 3,20 $\mu \mathrm{g} / \mathrm{L}$ (9). Neste estudo, os autores recomendam considerar os valores de Tg no plano do tratamento de câncer papilar de tireoide T1. Por outro lado, numa pesquisa realizada na Itália, observou-se que valores da Tg pré-ablação tomada 40 dias depois da cirurgia, maiores do que $67,9 \mathrm{ng} / \mathrm{mL}$, têm um valor preditivo positivo maior do que $90 \%$ para a presença de metástase (10). Numa outra pesquisa, realizada na França, foi observado que níveis de Tg maiores de $30 \mathrm{ng} / \mathrm{mL}$ indicam um fator de risco independente para a predição de progressão da doença $(\mathrm{OR}=10,1 ; 95 \% \mathrm{CI}=$ $4.0-25,7 ; P<0,001)$.

Neste artigo, apresentamos os resultados obtidos depois de estudar a relação entre os níveis de tiroglobulina pré-ablação e a persistência/ recorrência precoce de câncer diferenciado de tireoide numa amostra de indivíduos tratados, numa clínica especializada de Bogotá (Colômbia), durante o período compreendido entre janeiro de 2006 e janeiro de 2010. Considerou-se uma avaliação dos níveis de $\mathrm{Tg}$ antes da cirurgia e ablação, outra três meses depois da mesma e um ano depois, mais uma.

\section{Materiais e métodos}

Realizou-se um estudo retrospectivo no qual foram avaliados 314 registros clínicos de pa- cientes com diagnóstico de câncer diferenciado de tireoide que foram submetidos à terapia ablativa pós-cirúrgica com I-131, no período compreendido entre janeiro de 2006 e janeiro de 2010. Todos os participantes tinham dados dos níveis de tiroglobulina pré-ablação com avaliações clínicas e paraclínicas durante ou um ano depois de realizada a terapia. Consideraram-se como critérios de exclusão: ter câncer de tireoide diferente dos diferenciados, não ter dados de seguimento, apresentar tireoidectomia parcial, não ter ablação pós-cirúrgica com I-131 e ser exposto a I-131 para fins terapêuticos (por exemplo, indivíduos com recaída ou metástases conhecidas). As cirurgias foram realizadas por cirurgiões de cabeça e pescoço em diferentes centros hospitalares, mas o procedimento de ablação foi efetuado numa instituição considerada centro de referência para a doença no país. A dose terapêutica foi estabelecida de acordo com a presença de fatores de risco hispatológicos e clínicos para recorrência persistência da doença, de modo que, se o indivíduo era classificado como de baixo risco, empregava-se entre $50 \mathrm{e}$ $100 \mathrm{mCi}$ e para pacientes com alto risco uma dose igual ou maior a $150 \mathrm{mCi}$. Um paciente foi classificado como de alto risco quando era um indivíduo de 45 anos ou se tinha alguma patologia com uma das seguintes características: margens de ressecção comprometidas, subtipo histológico de células altas, esclorosante ou insular, comprometimento capsular ou de tecido perotireóideo, comprometimento macroscópico regional e comprometimento de gânglios linfáticos. Em caso de não ter sido observado nenhum dos fatores descritos, o paciente foi classificado como de baixo risco para fazer recorrência-persistência. Para estabelecer de maneira descritiva a relação entre a Tg pré-ablação e a presença de recaída \persistência um ano depois do tratamento, identificaram-se dois grupos de pacientes, considerando os valores extremos 
(mínimo e máximo) de Tg prévia, de modo que se formou um grupo de indivíduos que apresentaram Tg pós-ablação maior ou igual a $2 \mathrm{ng} \backslash \mathrm{ml}$ (recorrentes), cujo menor valor de TG prévia foi de $24 \mathrm{ng} \backslash \mathrm{ml}$ (grupo 1), e um grupo com os indivíduos cuja Tg pós-ablação foi menor que $2 \mathrm{ng} \backslash$ $\mathrm{ml}$ (não recorrentes), com valor de Tg prévia menor ou igual a $2,7 \mathrm{ng} \backslash \mathrm{ml}$. O procedimento ablativo foi realizado entre um e quatro meses após a cirurgia devido a que muitos dos pacientes tinham sido avaliados em outras instituições da cidade e do país. A coleta das amostras para quantificação da tiroglobina estimulada pré-terapia foi realizada uma semana antes da terapia, e em todos os casos foi realizada uma medição de TSH para garantir valores maiores a $30 \mathrm{mU} \backslash \mathrm{L}$, graças à liberação (suspensão da suplência de levotiroxina 3 a 4 semanas antes da terapia. Todas as medições de Tg foram obtidas utilizando técnicas imunométricas e considerando uma sensibilidade de $0,1 \mathrm{ng} / \mathrm{ml}$.

Para realizar a análise estatística de dados, o grupo de indivíduos foi dividido em três, tendo-se como critério os valores observados de Tg pré-ablação e a presença de recorrência/ persistência da seguinte forma: tomou-se como ponto de corte para estabelecer recorrência/ persistência haver uma Tg maior ou igual a $2 \mathrm{ng} / \mathrm{mL}$. Baseado nesse critério avaliaram-se os valores de Tg pré-ablação dos pacientes. No grupo de indivíduos classificados como não recorrentes, estabeleceu-se o maior valor de Tg pré-ablação e no grupo de indivíduos recorrentes estabeleceu-se o menor valor de $\mathrm{Tg}$ pré-ablação, de modo que no terceiro grupo ficaram aqueles indivíduos que compartilhavam valores de Tg pré-ablação sem importar se eram ou não recorrentes/persistentes. $\mathrm{Na}$ análise de dados, foi utilizado o teste de Kolmogorov Smirnov para se avaliar o ajuste das observações de variáveis contínuas (valores da $\mathrm{Tg}$ ) à distribuição normal de probabilidades. Como os testes de normalidade rejeitaram a hipótese de normalidade, decidiu-se utilizar métodos próprios da estatística não paramétrica, como o coeficiente de correlação de Spearman, o teste U de Mann Withney e o teste W de Wilcoxon, considerando-se estatisticamente significativos valores p menores ou iguais a 0,05.

\section{Resultados}

Das 314 fichas clínicas avaliadas, foram excluídas 40 por não apresentarem o dado da $\mathrm{Tg}$ pré-ablação, 36 porque pertenciam a indivíduos com presença de anticorpos anti-tiroglobulina, 40 porque tinham recebido a dose de I-131 com intenção terapêutica, 39 porque não tinham todos os dados de seguimento durante o primeiro ano pós-ablação e 74 porque seu seguimento foi realizado em instituições diferentes àquela do estudo. Foram incluídas 85 fichas de pacientes com câncer diferenciado de tireoide do tipo histológico papilar, 70 mulheres (81,3\%) e 15 homens $(18,7 \%)$, com idades entre 12 e 86 anos, (média de 46,9 anos, desvio padrão de $13,9)$. Cinco dos pacientes $(5,5 \%)$ foram submetidos à tiroidectomia total, em 60 (70,3\%) houve tireoidectomia total com esvaziamento central, em 18 (22\%), tireoidectomia total com esvaziamento central e radical modificado de colo unilateral e, em dois $(2,2 \%)$, houve tireoidectomia total com esvaziamento central e radical modificado de colo bilateral.

Segundo a tabela 1 , uma porcentagem maior de homens apresentou persistência/recorrência em comparação com as mulheres, ao passo que as distribuições são bastante similares quando avaliadas estratificando-se por idade. No caso dos subtipos histológicos, aproximadamente a metade dos pacientes com células altas (alto risco) apresentou recorrência/persistência e um número importante de casos de progressão aconteceu nas variantes de baixo risco folicular e mista. A frequência de recorrência/persis- 
Tabela 1. Características clínicopatológicas dos pacientes nos grupos com e sem progressão da doença

\begin{tabular}{|c|c|c|c|c|c|}
\hline \multirow{3}{*}{ Características clínicopatólogicas } & & \multicolumn{4}{|c|}{ Persistência/Recorrência } \\
\hline & & \multicolumn{2}{|l|}{ Sim } & \multicolumn{2}{|l|}{ Não } \\
\hline & & $\mathrm{N}$ & $\%$ & $\mathrm{~N}$ & $\%$ \\
\hline \multirow[t]{2}{*}{ Sexo } & Feminino & 13 & 18,6 & 57 & 81,4 \\
\hline & Masculino & 5 & 33,3 & 10 & 66,7 \\
\hline \multirow[t]{2}{*}{ Idade $\left(\right.$ anos) ${ }^{\circ}$} & $<45$ & 6 & 18,2 & 27 & 81,8 \\
\hline & $\geq 45$ & 12 & 23,1 & 40 & 76,9 \\
\hline \multirow[t]{6}{*}{ Subtipo histológico } & Clássico & 3 & 8,6 & 32 & 91,4 \\
\hline & Folicular & 4 & 25,0 & 12 & 75,0 \\
\hline & Clássico e folicular & 2 & 18,2 & 9 & 81,8 \\
\hline & Células altas & 9 & 45,0 & 11 & 55,0 \\
\hline & Células insulares & 0 & 0,0 & 1 & 100 \\
\hline & Sólido & 0 & 0,0 & 2 & 100 \\
\hline \multirow[t]{2}{*}{ Comp. Peritiróideo } & Sim & 13 & 31,7 & 28 & 63,8 \\
\hline & Não & 5 & 11,4 & 39 & 88,6 \\
\hline \multirow[t]{2}{*}{ Comp. capsular } & Sim & 14 & 26,9 & 38 & 73,1 \\
\hline & Não & 4 & 12,1 & 29 & 87,9 \\
\hline \multirow[t]{2}{*}{ Tamanho (mm) } & $<40$ & 14 & 18,9 & 60 & 81,1 \\
\hline & $\geq 40$ & 4 & 36,4 & 7 & 63,6 \\
\hline \multirow[t]{2}{*}{ Invasão macroscópica } & Sim & 5 & 71,4 & 2 & 28,6 \\
\hline & Não & 13 & 16,7 & 65 & 83,3 \\
\hline \multirow{2}{*}{$\begin{array}{l}\text { Margens de ressecção compro- } \\
\text { metidos }\end{array}$} & Sim & 5 & 31,2 & 11 & 68,8 \\
\hline & Não & 13 & 18,8 & 56 & 81,2 \\
\hline \multirow[t]{2}{*}{ Comp. ganglionar } & Sim & 16 & 30,2 & 37 & 69,8 \\
\hline & Não & 2 & 6,2 & 30 & 93,8 \\
\hline \multirow{3}{*}{$\begin{array}{l}\text { Grupo ganglionar compro- } \\
\text { metido }\end{array}$} & Central & 8 & 22,9 & 27 & 77,1 \\
\hline & Lateral & 0 & 0.0 & 1 & 100 \\
\hline & Central e lateral & 8 & 47,1 & 9 & 69,8 \\
\hline
\end{tabular}

Idade no momento do diagnóstico. \% sobre o total de indivíduos que apresentaram a característica clinicopatológica.

tência foi maior em indivíduos com invasão macroscópica, comprometimento peritireóideo e comprometimento ganglionar ( $\mathrm{p}=0.0004$, $\mathrm{p}=0.021$ e $\mathrm{p}=0.007$, respectivamente). A Tg pre -ablação (Tg1) quantificada em todos os casos sob um contexto de TSH $>30 \mathrm{MU} / \mathrm{L}$ (mediana $62,0 \mathrm{MU} / \mathrm{L})$, apresentou valores entre 0,1 e 672 ng/ML (mediana 3,5 ng/ML). Na avaliação pósterapia, observou-se que 59 pacientes $(69,4 \%)$ tinham captação exclusiva pelo remanescente tireóideo, seis apresentaram metástase em gân- glios de pescoço, 11 em gânglios mediastinais, um fez metástase pulmonar, 2 em gânglios e pulmões - cervicais ou mediastinais- e em seis indivíduos apresentou-se metabolismo hepático do hormônio radiomarcado sem captação no leito tiróideo nem alvos de retenção anormal. Todos os pacientes com metástase pulmonar (com ou sem comprometimento ganglionar associado) apresentaram persistência ao final do primeiro ano (tabela 2). Entre os 72 (84,7\%) indivíduos com resultados de raios-X de tórax, 
Tabela 2. Resultados obtidos na avaliação pós-ablação nos pacientes com e sem progressão da doença

\begin{tabular}{lcccc}
\hline & \multicolumn{3}{l}{ Persistência/Recorrência } & \\
\cline { 2 - 5 } & Sim & Não & \\
\cline { 2 - 5 } & No de pacientes & $\%$ & No de pacientes & $\%$ \\
\hline Metástases em gânglios de pescoso & 1 & 16,7 & 5 & 83,3 \\
Metástases em gânglios mediastinais & 3 & 27,3 & 8 & 72,7 \\
Metástase pulmonar & 1 & 100 & 0 & 0,0 \\
Remanescente em leito tireóideo & 10 & 16,9 & 51 & 83,1 \\
Metástases em pulmões e gânglios cervicais ou mediasti- & 2 & 100 & 0 & $0,0 \%$ \\
nais & 1 & 16,7 & 5 & $83,3 \%$ \\
Somente metabolismo hepático de hormônio radiomarcado & & & & \\
\hline
\end{tabular}

71 deles tinham avaliação normal ou não sugestiva de comprometimento metastásico, um dos pacientes tinha nódulos de provável origem metastásica. Realizaram-se ecografias de pescoço a 54 indivíduos $(63,5 \%)$, dos quais, em oito $(14,8 \%)$, identificaram-se adenopatias suspeitas de malignidade e, em um $(1,8 \%)$, tecido tumoral residual no leito. Esses nove pacientes assim como outro que tinha adenomegalia identificada através de exame clínico, foram verificados com biopsia, observando-se que seis biópsias não tinham tecido neoplásico e as demais sim. Estudos de extensão adicionais (TAC, RNM, Rastreio com 99MTc-Sestamibi o РЕT/СT) foram realizados em 13 pacientes, dos quais quatro apresentaram, em pelo menos um dos exames, resultados compatíveis com doença recorrente/persistente à distância e no restante destas avaliações apresentaram resultados não compatíveis com a presença de persistência/ recorrência. Finalmente, 20 indivíduos apresentaram persistência/recorrência da doença ao final do ano de seguimento, três dos casos tinham persistência/recorrência locorregional, sete metástases à distância, três persistência/ recorrência locorregional e à distância e sete casos apresentavam evidência bioquímica ou doença microscópica (Tg alta, somente).

\section{Ánalise pré-pós da Tiroglobulina}

Os valores das medianas da Tg1 no grupo completo aparecem bem menores quando são comparadas com os observados no grupo de indivíduos que apresentaram persistência/ recorrência um ano depois do procedimento. Em geral, a tendência da Tg no tempo é diminuir, mas é importante observar que a queda é menor nos indivíduos que têm altos valores iniciais do marcador, característica que identifica os pacientes que constituem o grupo de persistentes/recorrentes. (tabela 3). O teste para dados correlacionados permitiu estabelecer que a distribuição da $\operatorname{Tg} 1$ apresenta diferenças estatisticamente significantes $(\mathrm{p}=0,000$ para grupo geral e grupo recorrente/persistente) quando é comparada com os valores obtidos no segundo (Tg2) e terceiro momento (Tg3), mas entre a Tg2 e a Tg3 essa diferença não é significante. ( $p=0,062$ e $p=554$, respectivamente), enquanto no grupo de indivíduos sem persistência/recorrência essa diferença é estatisticamente significante $(\mathrm{p}=0,000)$. No grupo de indivíduos persistentes/recorrentes, os mínimos e máximos baixam entre a Tg1 e a $\mathrm{Tg} 2$, mas aumentam entre a $\mathrm{Tg} 2$ e a $\mathrm{Tg} 3$, fato que não acontece no outro grupo (tabela 3). Ao se comparar os níveis de Tg entre os grupos de pacientes (recorrentes vs não recorrentes) 
Tabela 3. Valores pré - pós e entre grupos da tireoglobulina

\begin{tabular}{|c|c|c|c|c|}
\hline $\begin{array}{l}\text { Grupo completo } \\
\mathrm{n}=85\end{array}$ & & $\operatorname{Tg} 1$ & $\operatorname{Tg} 2$ & $\operatorname{Tg} 3$ \\
\hline Mediana & & 3,5000 & 0,30000 & 0,10000 \\
\hline Mínimo & & 0,10 & 0,000 & 0,000 \\
\hline Máximo & & 672,00 & 101,000 & 220,000 \\
\hline \multicolumn{5}{|c|}{ Pacientes com persistência/recorrência } \\
\hline \multirow{3}{*}{$\operatorname{Sim} n=18$} & Mediana & 70,7500 & 10,45000 & 8,50000 \\
\hline & Mínimo & 2,70 &, 100 & 2,100 \\
\hline & Máximo & 672,00 & 101,000 & 220,000 \\
\hline \multirow{3}{*}{ Não $n=67$} & Mediana & 3,1000 & 20000 &, 10000 \\
\hline & Mínimo & 10 & ,000 & ,000 \\
\hline & Máximo & 24,00 & 16,600 & 1,460 \\
\hline
\end{tabular}

observou-se que, para cada um dos momentos de medição, as distribuições dos valores de $\mathrm{Tg}$ apresentaram diferenças estatisticamente significantes $(\mathrm{p}=0,000)$.

Grupos estabelecidos por níveis da Tg1 e a persistência/recorrência $\mathrm{O}$ estudo das distribuições dos dados da $\mathrm{Tg}$ permitiu estabelecer que há valores de Tg1 que são comuns para indivíduos com e sem persistência/recorrência, evidência que permitiu definir dois grupos adicionais de indivíduos, o primeiro formado por 14 indivíduos persistentes/recorrentes com níveis de Tg1 entre $24 \mathrm{ng} / \mathrm{mL}$ e $672 \mathrm{ng} / \mathrm{mL}$ (grupo 1) e um grupo de 32 pacientes sem persistência/recorrência com valores de Tg1 oscilando entre $0,1 \mathrm{ng} / \mathrm{mL}$ e $2,70 \mathrm{ng} / \mathrm{mL}$ (grupo 2). Dentro do primeiro grupo, observou-se que $78 \%$ (14/18) dos indivíduos apresentou persistência/recorrência um ano depois da ablação, enquanto que, no outro grupo a probabilidade estimada foi de 0.48 (32/67) para apresentar o evento de interesse. No grupo 1, a idade oscilava entre os 12 e os 86 anos (média: 50 anos), dos quais oito $(57,1 \%)$ tinham mais de 44 anos, $78,6 \%$ eram mulheres, sete tinham sido submetidos à tireoidectomia total com esvaziamento central, cinco à tireoi- dectomia total, além de esvaziamento central e radical modificado de pescoço unilateral e dois à tireoidectomia total com esvaziamento central e radical modificado de colo bilateral. Seis dos pacientes tinham células altas, quatro, células foliculares, três tinham subtipo histológico clássico e uma pessoa tinha subtipo clássico e folicular. Em quatro indivíduos deste grupo o tamanho do tumor foi maior ou igual a $40 \mathrm{~mm}$, dez deles tinham comprometimento peritireóideo, dez tinham comprometimento capsular, quatro apresentavam invasão macroscópica, cinco comprometimento das margens de ressecção e 13 tinham comprometimento de gânglios linfáticos. Esses indivíduos receberam entre 130 e 172 mCi (média 154 mCi) de I-131 como dose de ablação, três deles apresentaram recaída/persistência do tipo locorregional, quatro tinham metástases à distância, três apresentavam recaída locorregional e à distância e quatro tinham bioquímica ou doença microscópica. Dentro do grupo 2, as idades oscilavam entre os 21 e 71 anos (média de 47 anos); 21 pessoas estavam com mais de 44 anos. 93,8\% eram mulheres, 28 foram tratadas com tireoidectomia total, além de esvaziamento central, quatro tinham também esvaziamento radical modificado de pescoço unilateral e não foram 
encontrados indivíduos com esvaziamento bilateral adicional. Quanto ao subtipo histológico, 13 apresentavam subtipos clássicos, seis foliculares, seis mistos, seis de células altas e um indivíduo apresentava subtipo sólido. Somente um indivíduo tinha um tamanho de tumor maior ou igual a $40 \mathrm{~mm}, 10$ apresentavam comprometimento peritireóideo, 16, capsular, dois, comprometimento das margens de ressecção e 19 tinham os gânglios linfáticos comprometidos. Não se encontraram casos de pacientes com invasão macroscópica e a dose de I-131 que receberam esteve entre 50 e $220 \mathrm{mCi}$ (média $150 \mathrm{mCi}$ ). As características clinicopatológicas reconhecidas como preditores de progressão da doença que apresentaram associação estatisticamente significante com o desenlace foram o comprometimento peritireóideo $(\mathrm{p}=0,022)$, o comprometimento das margens de ressecção $(\mathrm{p}=0,020)$, tamanho de tumor maior ou igual a $40 \mathrm{~mm}(\mathrm{p}=0,025)$, o comprometimento de gânglios linfáticos $(\mathrm{p}=0,022)$ e a invasão macroscópica $(\mathrm{p}=0,006)$. Na Tabela 4, apresentase o comportamento dos níveis da Tg nos três momentos de avaliação dentro dos grupos 1 e 2 . De acordo com os resultados da tabela 4 , a $\mathrm{Tg}$ diminui em forma parecida nos dois grupos (por volta de $85 \%$ ) entre o momento da ablação e três meses ou seis meses depois da mesma, um fato similar acontece quando observamos a diferença entre o momento antes da ablação e entre nove ou doze meses depois. Porém, a diferença observada é importante quando se compara a diferença entre as medições para os momentos dois e três já que no grupo 1 de indivíduos a $\mathrm{Tg}$ disminui numa quantidade $(20 \%)$ menor em relação ao outro grupo (50\%) (tabela 4).

Tabela 4. Comparação da diminuição média (medianas) da Tg entre momentos para os subgrupos estabelecidos.

\begin{tabular}{llrrrrrr}
\hline \multicolumn{1}{c}{ Grupo } & $\begin{array}{c}\text { Estatístico } \\
\text { descritivo }\end{array}$ & Tg1 & Tg2 & Tg3 & $\begin{array}{c}\text { D1 } \\
(\%)\end{array}$ & $\begin{array}{c}\text { D2 } \\
(\%)\end{array}$ & $\begin{array}{c}\text { D3 } \\
(\%)\end{array}$ \\
\hline Subgrupo com persistência/recorrência & Mediana & 117,5 & 12,5 & 9,95 & 89,40 & 20,40 & 91,53 \\
n = 14 & Mínimo & 24,8 & 1,5 & 2,6 & & & \\
& Máximo & 672,0 & 101,0 & 220,0 & & & \\
Subgrupo sem persistência/recorrência & Mediana & 0,59 & 0,10 & 0,05 & 83,05 & 50,00 & 91,52 \\
n=32 & Mínimo & 0,10 & 0,00 & 0,00 & & & \\
& Máximo & 2,6 & 16,6 & 0,84 & & & \\
\hline
\end{tabular}

D1: Índice de diminuição entre Tgl e Tg2, D2: Índice de diminuiç̄õo entre Tg2 e Tg3, D3: Índice de diminuiç̃o entre Tg1 e Tg3.

\section{Discussão}

Neste estudo, foi documentado e analisado o comportamento pré e pós da Tireoglobulina em relação ao desenlace clínico precoce de 85 pacientes com carcinoma papilar de tireóides tratados com ablação, depois de serem submetidos à tireoidectomia. A presença bioquímica da doença, ao final do período de seguimento de um ano, foi definida por níveis de Tg suprimida maiores a $2 \mathrm{ng} / \mathrm{mL}$ (quantificada durante a terapia de suplência/supressão com levoti- roxina) $(2,15)$ ou por níveis de Tg liberada/ estimulada maiores a $5 \mathrm{ng} / \mathrm{mL}$, três ou quatro semanas depois de se suspender a levotiroxina, ou finalmente estimulada com TSHrh ao final do primeiro ano.

Apesar de que o valor da Tg como marcador tumoral seja de grande importância no seguimento após a ablação, ainda é bastante controvertido seu uso como preditor quando a medição é realizada antes do procedimento ablativo. A cinética de desaparição da Tg após 
a cirurgia é um reflexo fiel do volume remanescente ou da presença de células tumorais residuais, embora com um tempo médio mais longo em pacientes com metástase (16). Dessa forma, conforme nossos resultados, naquelas pessoas submetidas à tiroidectomia total ou quase total (apresentam menos de $1 \mathrm{~g}$ de tecido tireóideo residual), presume-se que os níveis altos de Tg pré-ablação representam doença extratireóidea locorregional ou à distância (micro ou macroscópica), no qual os maiores níveis de Tg pré-ablação estiveram associados à presença de persistência/recorrência e os menores ao sucesso da terapia ablativa.

É possível, então, considerar a possibilidade de utilizar o conhecimento dos níveis da $\mathrm{Tg}$ pré-ablação como mais um dos critérios para a predição de progressão entre os critérios atualmente reconhecidos (2-4) na abordagem do paciente com câncer de tireóide. Dado que o nível sérico da Tg aparentemente tem relação com o sucesso da ablação mediado pela dose de I-31(17,18), a mesma seria útil para estabelecer os valores da dose de I-131 recomendada segundo o risco estimado de falha no tratamento33 e futuramente, de acordo com Vaisman e cols, poderia ser de grande utilidade para decidir se é pertinente submeter a procedimento ablativo os pacientes com baixo risco (13).

Neste estudo, foi demonstrado que existe uma relação estatisticamente significante entre os níveis séricos da Tg pré-ablação e o desenlace da doença ao final do primeiro ano de seguimento $(p=0,000)$, assim como se demonstrou que o comportamento do marcador tumoral é diferente entre os pacientes que fazem persistência/recorrência $(p=0,000)$ em relação àqueles que não fazem; o que implica que indivíduos com altos níveis de $\mathrm{Tg}$ antes da ablação, continuavam apresentando valores de $\mathrm{Tg}$ significativamente superiores como reflexo da persistência tumoral após a administração de iodo radiativo. Esse resultado se evidencia ao observar-se que no grupo de pessoas persistentes/recorrentes não se apresentaram diferenças estatisticamente significantes entre os níveis de Tg2 e Tg3 $(p=0,507)$ e $57 \%$ dos indivíduos apresentaram aumento nos valores da $\mathrm{Tg}$ entre o primeiro e segundo semestre de seguimento.

Até o momento, poucos estudos têm se concentrado na pesquisa da capacidade prognóstica do valor da $\mathrm{Tg}$ (no momento da ablação, póscirúrgica ou pós-ablativa) e a questão de ter um ponto de corte para os níveis de Tg pré-ablação que permita estabelecer a priori a probabilidade de ser pesistente/recorrente, torna-se de grande importância para dar ao marcador características de preditor. Os limiares avaliados são diversos e a maioria deles arbitrários (desde os 2 ng/ML até $100 \mathrm{ng} / \mathrm{ML}$ ) o que tem levado a se recomendar que cada instituição identifique seus próprios valores (Heemstra e cols). Giovanella e cols constataram que, em indivíduos com baixo risco, valores menores a $3.20 \mathrm{ng} / \mathrm{ML}$ na Tg estão associados $93 \%$ das vezes a indivíduos com ausência de persistência/recorrência, enquanto que Kim e cols constataram que valores da Tg pré-ablação menores ou iguais a $2 \mu \mathrm{g} /$ ML tem um valor preditivo negativo de 98,4\% (IC95 \% de 94,4-99,8\%), sendo esse valor um limiar estabelecido de forma arbitrária (12). Lee HJ e cols mostraram que o sucesso da ablação difere significativamente de acordo com o nível de $\mathrm{Tg}$ no momento de realizar o procedimento com taxa de sucesso de $96,6 \%$ quando a Tg é menor que 10ng/ML $(\mathrm{P}<0,001)$, e concluíram que é importante realizar um seguimento mais rigoroso, ajustando-se às intervenções terapêuticas (8). Polachek e cols mostraram que o limiar arbitrário de $10 \mathrm{ng} / \mathrm{ML}$ identificou pacientes com doença persistente como um fator independente com VPN $89 \%$ (19). No estudo de Cabezón e cols, foram analisados cinco postos de valores arbitrários e o valor de Tg menor a 10 
ng/ML apresentou uma relação estatisticamente significante com a ausência de persistência/ recorrência $(\mathrm{p}<0,003)(20)$.

Nesta pesquisa encontraram-se dois valores que poderiam ser pontos de corte, mas é preciso desenvolver pesquisas planejadas somente para atingir esse objetivo. Segundo este estudo, apresentar níveis de Tg pré-ablação menores a $2,7 \mathrm{ng} / \mathrm{ML}$ poderia ser visto como fator protetor, já que nesse posto de valores não foram observados casos de persistência/ recorrência, ao passo que ter níveis de Tg pré -ablação maiores a $24 \mathrm{ng} / \mathrm{ML}$ pode ser considerado um fator de risco. Em geral, se fossemos utilizar a Tg pré-ablação como preditor, essa teria alta capacidade para identificar pacientes com baixo risco de apresentar persistência/ recorrência precoce, enquanto que, na detecção de pacientes persistentes/recorrentes, essa capacidade é aparentemente menor e estaria afetada possivelmente pela produção de $\mathrm{Tg}$ nos remanescentes (de diversos tamanhos) ou nas micrometástases ganglionares que não foram totalmente eliminadas com a ablação (20). A respeito da possibilidade de se estabelecer 24 ng/ML como patamar útil na identificação de progressão precoce da doença; existem algumas pesquisas que têm estudado valores próximos como fatores de risco independentes. No caso de Toubeau e cols, estabeleceu-se o valor da $\mathrm{Tg}$ pré-ablação maior a $30 \mathrm{ng} / \mathrm{ML}(\mathrm{OR}=10,1 ; 95 \%$ IC $=4,0-25,7 ; P<0,001)(11)$. Hall e cols, por sua vez, identificaram níveis maiores a $20 \mathrm{ng} /$ ML (RR 5,1; 95 \% IC: 2,0-13,1) (14) e Heemstra e cols encontraram que o valor era $27,5 \mathrm{ng} / \mathrm{ML}$ ou mais (VPP $97 \%$ ) (21).

Os resultados sugerem que a Tg pré-ablação pode ser útil na tomada de decisões sobre a ablação e a necessidade de quantificação de $\mathrm{Tg}$ estimulada/liberada ao final do primeiro ano. É possível que pacientes com Tg pré-ablação maior a $24 \mathrm{ng} / \mathrm{ML}$ precisem de doses altas de I-131 e da quantificação de Tg estimulada/liberada ao final do primeiro ano, ao passo que é possível que indivíduos com valores de $\mathrm{Tg}$ pré-ablação menores a 2,7 ng/ML não precisem de doses altas de I-131 nem da quantificação estimulada/liberada.

No presente estudo, a quantidade de Tiroglobulina associada a cada indivíduo responde ao método de quantificação utilizado pelo laboratório em que o sistema de saúde envia o paciente, o qual não é o mesmo para todos os pacientes. Essa poderia ser uma limitante da pesquisa, já que não foi possível controlar a variabilidade, entre as medições, devida ao procedimento próprio utilizado pelo respectivo laboratório. Porém, em países como a Colômbia, onde o sistema de saúde não permite contar com um protocolo estabelecido e estandarizado para a realização de provas de laboratório como a quantificação de $\mathrm{Tg}$, o presente estudo é útil como uma primeira aproximação ao objetivo proposto.

\section{Referências}

1. Davies L, Welch HG. Increasing incidence of thyroid cancer in the United States, 1973-2002. JAMA. 2006;295(18):2164-7.

2. Cooper DS, Doherty GM, Haugen BR, Kloos R, Lee S, Mandel S, et al. Revised American Thyroid Association management guidelines for patients with thyroid nodules and differentiated thyroid cancer. Thyroid. 2009; 19(11):1167-214.

3. Pacini F, Castagna MG, Brilli L, Jost L. Differentiated thyroid cancer: ESMO clinical recommendations for diagnosis, treatment and follow-up. Ann Oncol. 2008;20(Suppl 4):143-6. 
4. Pitoia F, Ward L, Wohllk N, Friguglietti C, Tomimori E, Gauna A, et al. Recommendations of the Latin American Thyroid Society on diagnosis and management of differentiated thyroid cancer. Arq Bras Endocrinol Metabol. 2009;53(7):884-97.

5. Eustatia CF, Smit JW, Romijn JA, Van der Kleij-Corssmit EP, Pereira AM, Stokkel MP, et al. Diagnostic value of serum thyroglobulin measurements in the follow-up of differentiated thyroid carcinoma, a structured meta-analysis. Clin Endocrinol (Oxf). 2004; 61(1):61-74.

6. Sawka AM, Orlov S, Gelberg J, Stork B, Dowar M, Shaytzag M, et al. Prognostic value of postsurgical stimulated thyroglobulin levels after initial radioactive iodine therapy in well-differentiated thyroid carcinoma. Head Neck. 2008;30(6):693-700.

7. Arora A, Tolley NS, Tuttle RM. Editors. A Practical Manual of Thyroid and Parathyroid Disease. 1a ed. London: Blackwell Publishing; 2010.

8. Lee HJ, Rha SY, Jo YS, Kim SM, Ku BJ, Shong M, et al. Predictive value of the preablation serum thyroglobulin level after thyroidectomy is combined with postablation 131I whole body scintigraphy for successful ablation in patients with differentiated thyroid carcinoma. Am J Clin Oncol. 2007;30(1):63-8.

9. Giovanella L, Ceriani L, Ghelfo A, Keller F. Thyroglobulin assay 4 weeks after thyroidectomy predicts outcome in low-risk papillary thyroid carcinoma. Clin Chem Lab Med. 2005;43(8):843-7.

10. Ronga G, Filesi M, Ventroni G, Vestri AR, Signore A. Value of the first serum thyroglobulin level after total thyroidectomy for the diagnosis of metastases from differentiated thyroid carcinoma. Eur J Nucl Med. 1999;26(11):1448-52.

11. Toubeau M, Touzery C, Arveux P, Chaplain G, Vaillant G, Berriolo A, et al. Predictive value for disease progression of serum thyroglobulin levels measured in the postoperative period and after (131)I ablation therapy in patients with differentiated thyroid cancer. J Nucl Med. 2004;45(6):988-94.

12. Kim TY, Kim WB, Kim ES, Ryu JS, Yeo JS, Kim SC, et al. Serum thyroglobulin levels at the time of 131I remnant ablation just after thyroidectomy are useful for early prediction of clinical recurrence in low-risk patients with differentiated thyroid carcinoma. J Clin Endocrinol Metab. 2005;90(3):1440-5. Epub 2004 dec 21.

13. Vaisman A, Orlov S, Yip J, Hu C, Lim T, Dowar M, et al. Application of post-surgical stimulated thyroglobulin for radioiodine remnant ablation selection in low-risk papillary thyroid carcinoma. Head Neck. 2010;32(6):689-98.

14. Hall FT, Beasley NJ, Eski SJ, Witterick IJ, Walfish PG, Freeman JL. Predictive value of serum thyroglobulin after surgery for thyroid carcinoma. Laryngoscope. 2003;113(1):77-81.

15. Garavito G. Factores pronósticos para la recaída en pacientes con cáncer papilar de tiroides. Rev Colomb Cancerol. 2005;9(2):21-30.

16. Giovanella L, Ceriani L, Maffioli M. Postsurgery serum thyroglobulin disappearance kinetic in patients with differentiated thyroid carcinoma. Head Neck. 2010;32(5):568-71.

17. Tamilia M, Al-Kahtani N, Rochon L, Hier MP, Payne RJ, Holcroft CA, et al. Serum thyroglobulin predicts thyroid remnant ablation failure with $30 \mathrm{mCi}$ iodine- 131 treatment in patients with papillary thyroid carcinoma. Nucl Med Commun. 2011;32(3):212-20.

18. Rosario PW, Xavier AC, Calsolari MR. Value of postoperative thyroglobulin and ultrasonography for the indication of ablation and ${ }^{131} \mathrm{I}$ activity in patients with thyroid cancer and low risk of recurrence. Thyroid. 2011;21(1):49-53.

19. Polachek A, Hirsch D, Tzvetov G, Grozinsky-Glasberg S, Slutski I, Singer J, et al. Prognostic value of post-thyroidectomy thyroglobulin levels in patients with differentiated thyroid cancer. J Endocrinol Invest. 2011;34(11):855-60. 
20. Cabezón C, Löwenstein A, Orlandi A, Sartorio G, Sobrado P. Utilidad de la Tiroglobulina sérica preablación como predictor de evolución en los pacientes con carcinoma diferenciado de tiroides. Rev Argent Endocrinol Metab. 2011;48:25-33.

21. Heemstra KA, Liu YY, Stokkel M, Kievit J, Corssmit E, Pereira AM, et al. Serum thyroglobulin concentrations predict disease-free remission and death in differentiated thyroid carcinoma. Clin Endocrinol (Oxf). 2007;66(1):58-64. 